\title{
DE LESSENAAR VAN DOMELA NIEUWENHUIS
}

Toen de voorzitter van de Vereniging, W. van der Mandele, in 1951 onverwacht stierf, werd de secretaris bereid gevonden het roer over te nemen. O.J.Tj.N. Domela Nieuwenhuis (1894-1988) zou de taak 18 jaar lang gaan vervullen en in die periode kwamen veel dingen tot stand. Allereerst werd de verhuizing naar het Museum van Aziatische Kunst in het Rijksmuseum voltooid. In 1954 volgde onder zijn leiding de grote zomertentoonstelling Oosterse Schatten en werden er verschillende aankopen gedaan, waaronder het Cambodiaanse hoofd van een slapende Vishnu, het album van vingerschilderingen door Gao Qipei en een Japans $12^{\mathrm{c}}$-eeuws houten beeld van Amida Boeddha. ${ }^{1}$ De conservator van de collectie, Herman Visser, ging in 1956 na meer dan 30 jaar dienst met pensioen en zijn opvolger Jan Fontein maakte nog tijdens het voorzitterschap van Domela Nieuwenhuis de overstap naar het Museum of Fine Arts in Boston. Inmiddels werd de financiële armslag van de Vereniging steeds beperkter. Vlak nadat Domela Nieuwenhuis op 75-jarige leeftijd het stokje had overgegeven aan P. Formijne was het voor de Vereniging niet langer mogelijk om het Museum van Aziatische Kunst zelf te bekostigen en in 1972 werd de collectie uiteindelijk in langdurig bruikleen bij het Rijksmuseum ondergebracht en was de Afdeling Aziatische Kunst een feit.

Behalve kundig bestuurder was Domela Nieuwenhuis ook verzamelaar. Vooral Japans lakwerk had zijn aandacht. Vlak voor zijn terugtreden schonk hij de Vereniging bij haar 50-jarig jubileum een vijftal stukken, waaronder het bekendste voorwerp uit zijn collectie, de Japanse lessenaar die al in de jaren voor 1963 in bruikleen was gegeven (afb. 1). ${ }^{2}$ Het is een bijzonder rijk gedecoreerd stuk, dat een goed voorbeeld is van een hoogwaardig Japans meubel. Er is een lange traditie van luxe gebruiksgoederen in Japan en lakwerk neemt daarin een speciale plaats in. Lak beschermt hout tegen vraat van insecten en de in Japan gebruikelijke hoge schommelingen van temperatuur en luchtvochtigheid; het is licht van gewicht en dus makkelijk verplaatsbaar in het flexibele Japanse interieur. Bovendien biedt het bijna onuitputtelijke mogelijkheden voor versiering, die het voorwerp een ingetogen maar rijke uitstraling kan geven, of in dit geval een onverbloemd vertoon van luxe en overdaad. De achterkant van het blad, de standaard en de ladedoos zijn helemaal bedekt met een motief van krullende pioentakken, uitgevoerd in verschillende tinten uiterst dicht gestrooid goudpoeder (makie) en in bladvorm gesneden stukjes goudfolie, die elk omgeven worden door een met zorg geplaatst randje makie. Het is enorm arbeidsintensief en het maken van zo'n voorwerp duurde dan ook maanden. Eerst moesten de grondlagen en de zwarte ondergrond aangebracht worden: een dikke, uit tientallen lagen bestaande basis, die een diepzwarte achtergrond geeft waartegen de overdaad $2 \mathrm{pM}$ van helder goud goed uitkomt. Er is nergens op bezuinigd, zelfs de meestal access 

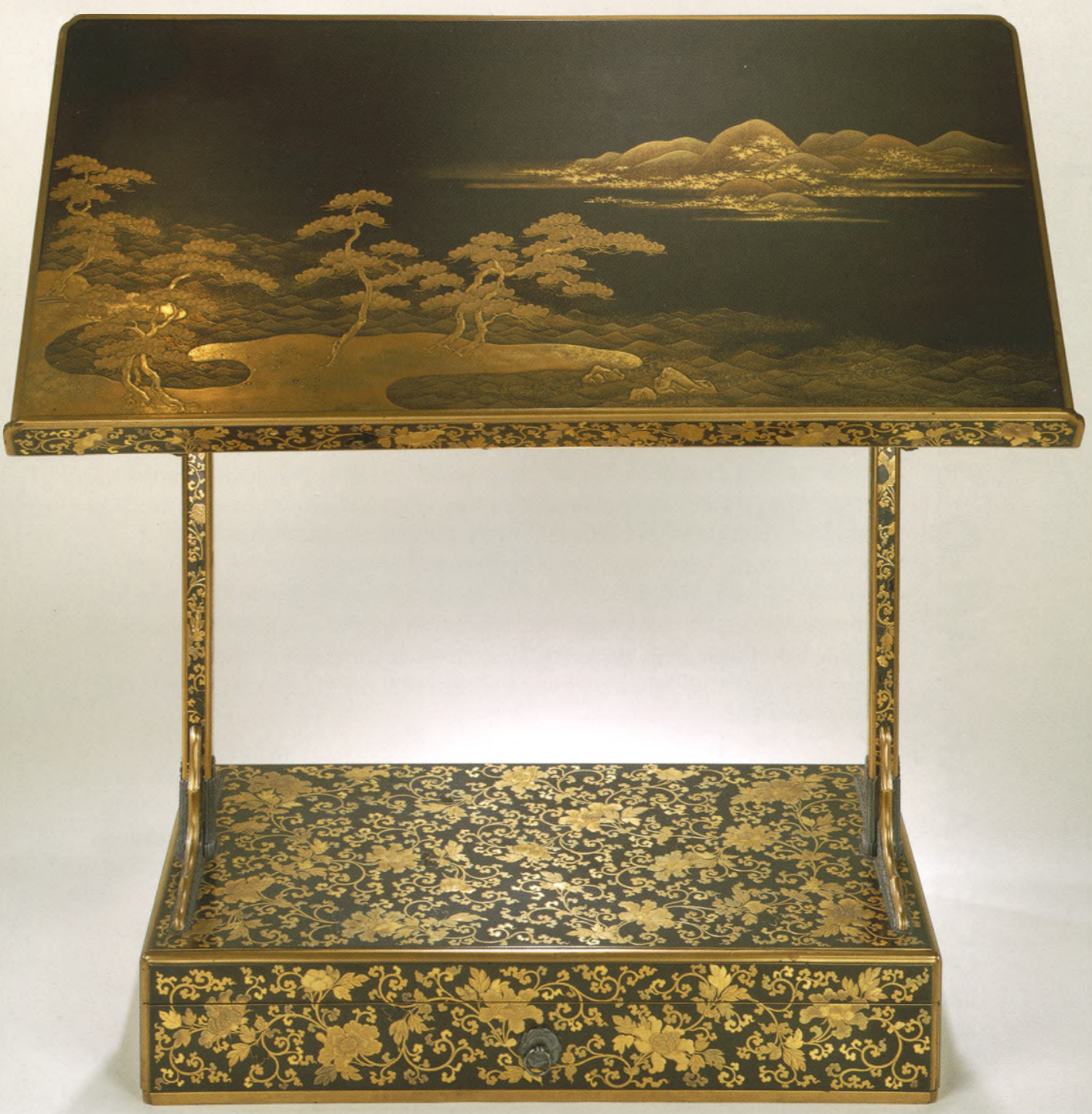
Afbeelding 1 (links) Lessenaar, lak op hout, $h$. $57 \mathrm{~cm}$., Japan, $18^{\circ}$ eeuw. Schenking O.J.Tj.N. Domela Nieuwenhuis, Rijksmuseum Amsterdam, collectie VVAK, AK-MAK-1183

\section{Afbeelding 2}

Yashima Gakutei (1786?1868), Hojo Tokiyori lezend bij het licht van een lamp, kleurenhoutsnede, Japan, Ca. 1822 , Rijksmuseum Amsterdam, RP-P-1990-407

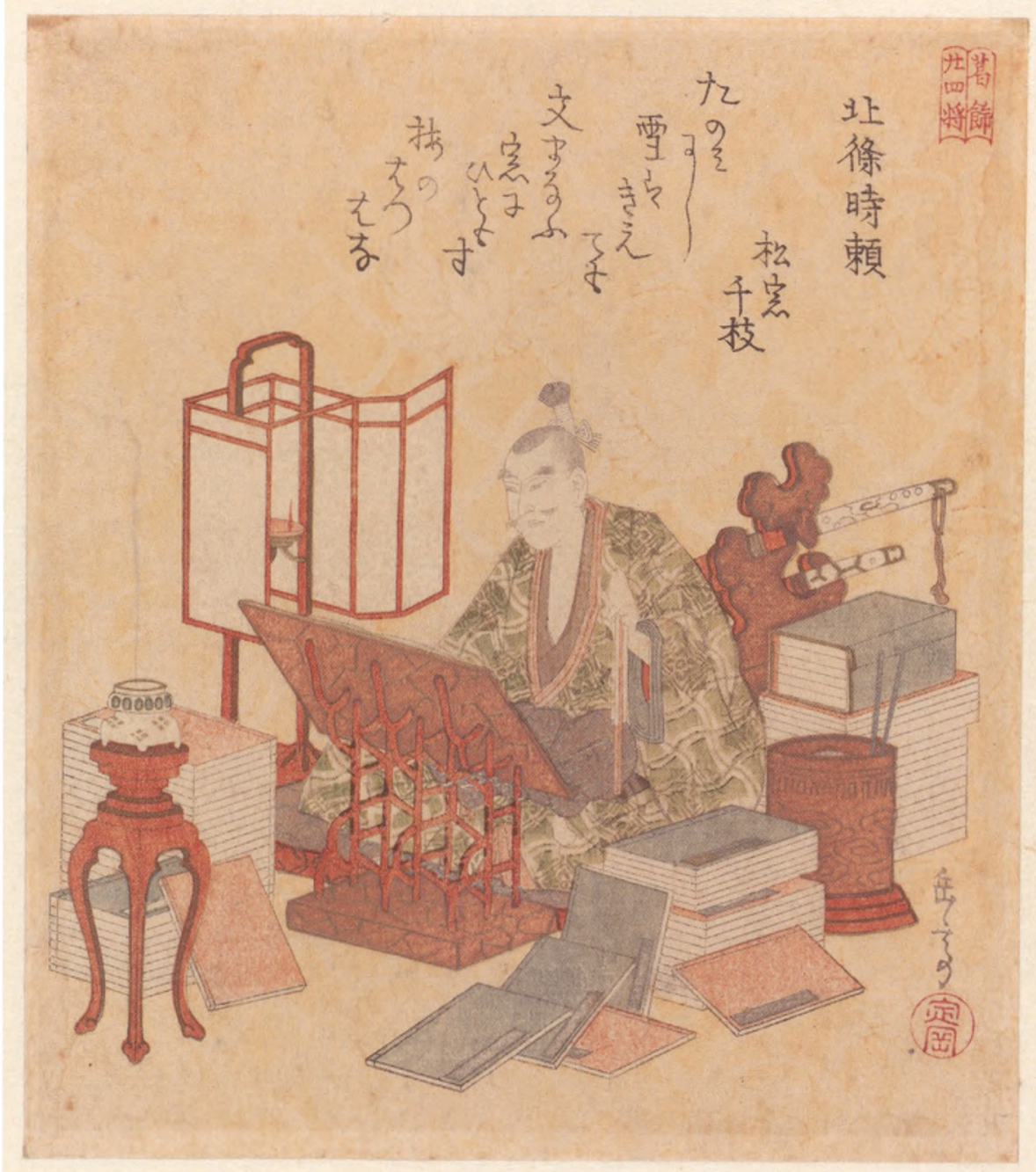

verborgen zij- en achterkanten van de lade zijn met het rijke patroon bedekt. De afbeelding op de lessenaar laat een aantal technieken zien. Ook hier is een aantal tinten goud makie te vinden, evenals ingelegde stukjes goudfolie, terwijl de golven en de heuvels op de achtergond zijn uitgevoerd in gepolijste versiering. Hierbij wordt de afbeelding in makie bedekt met lagen zwarte lak, die teruggepolijst worden zodat de versiering van onder het lakoppervlak wat onscherp oprijst. Op die manier kreeg het landschap diepte, met de golven die langzaam in de verte verdwijnen richting de nevelige heuvels. Het is de kust van Sumiyoshi met zijn pijnbomen aan het strand, een bekend thema in de Japanse kunst. ${ }^{3}$ Op die plek huist de God van Sumiyoshi, die behalve God van de Zeevaart ook God van de Dichtkunt is en dat is natuurlijk een mooi thema om af te beelden op een lessenaar.

Op een prent van Yashima Gakutei (1786?-1868) zit een $13^{\mathrm{e}}$-eeuwse geleerde te lezen bij het licht van een kaars in een opengeslagen papieren lantaarn. Voor hem een lessenaar, om hem heen stapels met boeken. Hôjô Tokiyori

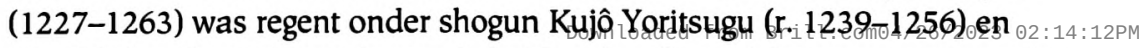
stond bekend om zijn rechtvaardigheid en kundige adviezen, wars văn enìg access 
machtsmisbruik. Gakutei heeft hem afgebeeld als een hardwerkende geleerde, laat in de avond verzonken in de boeken, maar met een nog onvermoeibare, scherpe blik in de ogen. De $18^{\mathrm{c}}$-eeuwse lessenaar die Domela Nieuwenhuis de Vereniging schonk zal wellicht niet aan zo'n illustere staatsman hebben toebehoord, maar gezien de rijke, wat statige versiering zal het toch zeker een lid van een daimyo-geslacht zijn geweest.

\section{Noten}

1. Respectievelijk AK-MAK-224, AK-MAK-290 en AK-MAK-294.

2. AK-MAK-1211, AK-MAK-1197, AK-MAK-1198, AK-MAK-1199. Jan Fontein schreef in 1963 een artikel waarin hij vermeldt dat de lessenaar toen al in bruikleen was. J. Fontein, 'Pijnbomen aan het strand', in: Bulletin van het Rijksmuseum 3 (1963), pp. 66-70.

3. Ibid. p. 68. Sumiyoshi komt ook voor in het No-toneelstuk Takasago, waarin twee geesten van pijnbomen, de een uit Takasago, de ander uit Sumiyoshi, optreden in de vorm van een oude man en vrouw. Hoewel ze uit twee ver verwijderde plekken komen, vormen ze een onafscheidelijk paar en zijn daarmee (met de pijnboom) symbool van lang leven en huwelijkse trouw. 